УДК 634.8:631.52

DOI 10.30679/2219-5335-2021-2-68-18-27

ЭМБРИОНАЛЬНАЯ

ПЛОДОНОСНОСТЬ НОВЫХ

ГИБРИДНЫХ ФОРМ

СТОЛОВОГО ВИНОГРАДА

В АГРОЭКОЛОГИЧЕСКИХ

УСЛОВИЯХ

КРАСНОДАРСКОГО КРАЯ*

Цику Дамир Муратович

аспирант, младший научный сотрудник

лаборатории управления

воспроизводством

в ампелоценозах и экосистемах

e-mail: mr.tsiku@mail.ru

Марморштейн Анна Александровна аспирант, младший научный сотрудник лаборатории управления воспроизводством в ампелоценозах и экосистемах e-mail: am342@yandex.ru

Петров Валерий Семенович д-р с.-х. наук ведущий научный сотрудник лаборатории управления воспроизводством в ампелоценозах и экосистемах e-mail: Petrov_53@mail.ru

Федеральное государственное бюджетное научное учреждение «Северо-Кавказский федеральный научный центр садоводства, виноградарства, виноделия», Краснодар, Россия

Наиболее важным приемом агротехники, направленным на повышение продуктивности и качества винограда является обрезка кустов, длина которой зависит от наиболее
UDC 634.8:631.52

DOI 10.30679/2219-5335-2021-2-68-18-27

\section{EMBRYONIC FRUITFULNESS OF NEW HYBRID FORMS \\ OF TABLE GRAPES \\ IN THE AGROECOLOGICAL \\ CONDITIONS \\ OF THE KRASNODAR REGION*}

Tsiku Damir Muratovich

Postgraduate, Junior Research Associate of Reproduction Control

in the Ampelocenoses

and Ecological Systems Laboratory

e-mail:mr.tsiku@mail.ru

Marmorshtein Anna Aleksandrovna

Postgraduate, Junior Research Associate of Reproduction Control in the Ampelocenoses and Ecological Systems Laboratory e-mail: am342@yandex.ru

Petrov Valeriy Semionovich Dr. Sci. Agr.

Leading Research Associate of Reproduction Control in the Ampelocenoses and Ecological Systems Laboratory e-mail: Petrov_53@mail.ru

Federal State Budget

Scientific Institution

«North Caucasian Federal

Scientific Center of Horticulture,

Viticulture, Wine-making»,

Krasnodar, Russia

The most important technique of agricultural technology to increase the productivity and quality of grapes is pruning of bushes, the length

\footnotetext{
* Исследование выполнено при финансовой поддержке Кубанского научного фонда в рамках научного проекта № МФИ - 20.1/20

* The study was carried out with financially supported of the Kuban Science Foundation within the framework of the scientific project No. MFI $-20.1 / 20$
} 
продуктивной зоны побегов.

Для определения зоны наибольшей продуктивности побега оценивается эмбриональная плодоносность глазков, зависящая от биологических особенностей сортов винограда и агроэкологических факторов местности как природных (погодно-климатические, почвенные и пространственные условия), так и антропогенных (содержание почвы, формировка кустов, применение удобрений и т.д.). В 2018 году нами были изучены особенности закладки и дифференциации соцветий новых гибридных форм столового винограда селекции С.Э. Гусева (г. Волгоград) в засушливых и жарких условиях Волгоградской области. В данной работе представлены результаты исследования эмбриональной плодоносности новых столовых гибридов Исполин, Кураж, Гамлет, Валенсия, Артек, Тимоти в Краснодарском крае. Изучение эмбриональной плодоносности гибридов выполнено на виноградниках, произрастающих в агроэкологических условиях центральной зоны Краснодарского края, подзона № 4. Отбор изучаемых побегов и оценку эмбриональной плодоносности зимующих глазков проводили в период глубокого физиологического покоя растений путем микроскопирования (Микромед МС1) в лаборатории СКФНЦСВВ. Установлена закономерность неодинаковой закладки и дифференциации эмбриональных соцветий у изучаемых гибридных форм винограда, а также дифференциация коэффициентов плодоносности и плодоношения по длине побегов. Самые высокие показатели плодоношения и плодоносности были у гибридов винограда Гамлет, Артек и Тимоти в условиях температурного стресса, наиболее высокая эмбриональная продуктивность наблюдалась в зоне 6-8 зимующих глазков.

Ключевые слова: ВИНОГРАД; СОРТ, ЭМБРИОНАЛЬНАЯ ПЛОДОНОСНОСТЬ, ДЛИНА ОБРЕЗКИ of which depends on the most productive zone of shoots. To determine the zone of the greatest production of the shoot, the embryonic fruitfulness of the buds is estimated, depending on the biological characteristics of the grape varieties and agroecological factors of the location, both natural (weather and climatic, soil and spatial conditions) and anthropogenic (management system, pruning, fertilizer use, etc.). In 2018, we studied the special aspects of inflorescences formation and differentiation of new table grapes hybrid forms of E.S. Gusev breeding (Volgograd) under the arid and hot conditions of the Volgograd. Territory in this work research results are presented of the embryonic fruitfulness of the new table grapes hybrid forms of Ispolin, Courage, Hamlet, Valencia, Artek, Timothy in the Krasnodar Region. The study of embryonic fruitfulness was carried out in the vineyards growing in the agroecological conditions of the Krasnodar Region Central Zone, subzone № 4. Selection of the studied shoots and assessment of the embryonic fruitfulness of buds under winter were carried out during the period of deep physiological rest of plants by microscopy (Micromed MS1) in the laboratory of NCFSCHVW. The regularity of different laying and differentiation of embryonic inflorescences in the studied grapes hybrid forms, as well as differentiated coefficients of fruitfulness and fruiting along the length of shoots are established. The highest rates of fruiting and fruitfulness were in the grape hybrids of Hamlet, Artek and Timothy under the conditions of temperature stress, the highest embryonic productivity was observed in the zone 6-8 wintering buds.

Key words: GRAPES; VARIETY, EMBRYONIC FRUITFULNESS, PRUINING LENGTH 
Введение. Обрезка кустов относится к одним из наиболее важных приемов агротехники, влияющих на продуктивность насаждений и качество винограда [1-4]. Обрезку побегов необходимо применять с учетом биологических особенностей генотипов и агроэкологических условий среды произрастания растений в целях эффективного управления продуктивностью и качеством винограда [5-8]. Длина обрезки побегов зависит от размещения продуктивной зоны побега, причем продуктивная зона у разных сортов меняется по длине побега [9-11]. Согласно существующим исследованиям в средней части побега находятся самые крупные и наиболее развитые эмбриональные соцветия [12-14], поэтому для максимальной реализации потенциала хозяйственной продуктивности растений винограда обрезка проводится с сохранением наиболее продуктивной зоны побегов [15-17].

Для наиболее точного определения продуктивной зоны побега оценивают параметры эмбриональной плодоносности репродуктивных органов виноградных растений [17]. На закладку эмбриональных соцветий влияют биологические особенности сорта и агроэкологические условия местности, в которой выращивается виноград $[18,19]$, а также способность генотипа закладывать определенное количество плодовых почек [20, 21].

К агроэкологическим условиям местности также относятся и антропогенные факторы, оказывающие определенное влияние на формирование эмбриональных соцветий $[22,23]$. У технического сорта винограда Бианка в насаждениях с уплотненной посадкой кустов (6666 шт./м²) отмечалось смещение продуктивной зоны эмбриональных соцветий к основанию побега при переходе от черного пара к залужению - на побегах винограда увеличивалось число зачаточных соцветий в зоне 1-3 глазков [22].

Ранее были установлены особенности закладки и дифференции эмбриональных соцветий у столовых гибридных форм винограда Агат Дубовский, Артек, Валенсия, Исполин, Кураж, Пестрый, Акелло, Гамлет, Киш- 
миш Дубовский и Дубовский красный в условиях континентального климата Волгоградской области. Для данного региона характерны холодная малоснежная зима и жаркое лето [24, 25]. Эмбриональная плодоносность данных гибридных форм ранее в условиях умеренно континентального климата в Краснодарском крае не изучалась.

В связи с этим целью данной работы являлось выявление закономерности закладки эмбриональных соцветий и оптимизация длины обрезки побегов винограда в агроэкологических условиях Краснодарского края.

Объекты и методы исследований. В качестве объекта исследований использовали новые гибридные формы столового винограда селекции С.Э. Гусева (г. Волгоград): Исполин, Кураж, Гамлет, Валенсия, Артек и Тимоти. Изучение эмбриональной плодоносности побегов у новых форм было выполнено на поливных виноградниках ИП КФХ Т.Б. Фисюра, в агроэкологических условиях центральной зоны Краснодарского края, в условиях повышенного температурного режима.

Отбор изучаемых побегов и оценку эмбриональной плодоносности зимующих глазков проводили в период глубокого физиологического покоя растений в 2020 году путем микроскопирования (Микромед МС1) в лаборатории СКФНЦСВВ. В процессе исследований установлена зависимость коэффициентов плодоношения и плодоносности эмбриональных побегов в центральных почках зимующих глазков от биологии сортов и установлена закономерность их изменения по длине побегов винограда.

Обсуждение результатов. Климат центральной агроэкологической зоны виноградарства Краснодарского края умеренно-континентальный. Среднегодовая температура воздуха составляет $+12,5 \ldots+13,0{ }^{\circ} \mathrm{C}$. Абсолютный минимум температур $--30{ }^{\circ} \mathrm{C}$, абсолютный максимум $-+40{ }^{\circ} \mathrm{C}$. Сумма атмосферных осадков за год составляет 700-800 мм. Почвы представлены выщелоченными черноземами [26]. 
Вегетационный период 2020 г. на участке исследований отмечался повышенным температурным режимом. Дата открытия виноградников в с. Красносельское Динского района - 15 апреля, на один день позже последних заморозков. Летние месяцы, в которые происходила закладка и дифференциация соцветий для урожая будущего года, характеризовались жаркой погодой. Относительная влажность достаточно часто для данного района опускалась ниже 30 \%, более половины лета температура воздуха поднималась выше $30{ }^{\circ} \mathrm{C}$. Максимальная температура достигала $+38^{\circ} \mathrm{C}$ [27].

В жарких летних условиях 2020 года коэффициент эмбрионального плодоношения у изучаемых гибридов винограда варьировал в интервале 0,49-0,65; плодоносности - 1,05-1,15 (рис. 1).

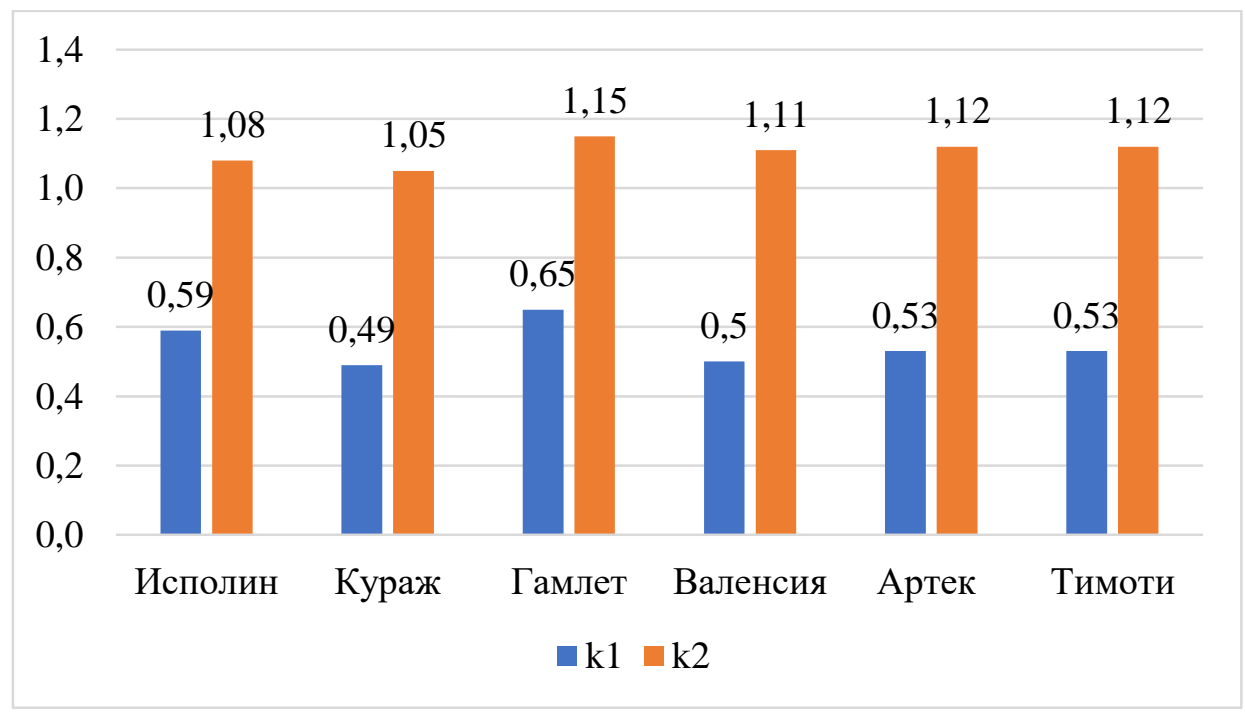

Рис 1. Показатели коэффициентов (К1) и (К2) у изучаемых гибридов винограда

По коэффициенту эмбрионального плодоношения (К1) выделились гибриды Гамлет $(0,65)$ и Исполин $(0,59)$. По сравнению с данными по Волгоградской области $[24,25]$, в условиях центральной зоны Краснодарского края K1 ниже у Исполина и Валенсии, выше - у Куража, Артека и Гамлета. По коэффициенту плодоносности (К2) выделились гибриды Гамлет $(1,15)$, Тимоти и Артек с идентичными показателями $(1,12)$. У гибридов Артек, Исполин, Кураж и Гамлет К2 данные показатели выше в условиях Краснодарского края по сравнению с Волгоградом. Указанные различия могут 
Плодоводство и виноградарство Юга России № 68(2), 2021 г.

быть объяснены отсутствием дефицита влаги в Краснодарском крае при капельном орошении.

По длине побега коэффициенты плодоношения и плодоносности были наибольшими в зоне 6 - 7 зимующих глазков (рис. 2). У гибрида Гамлет высокая эмбриональная продуктивность наблюдалась в зоне 5 - 7 зимующих глазков, поэтому для сохранения максимальной хозяйственной продуктивности винограда оптимальная длина обрезки побегов у гибрида Гамлет должна составлять 8 глазков.

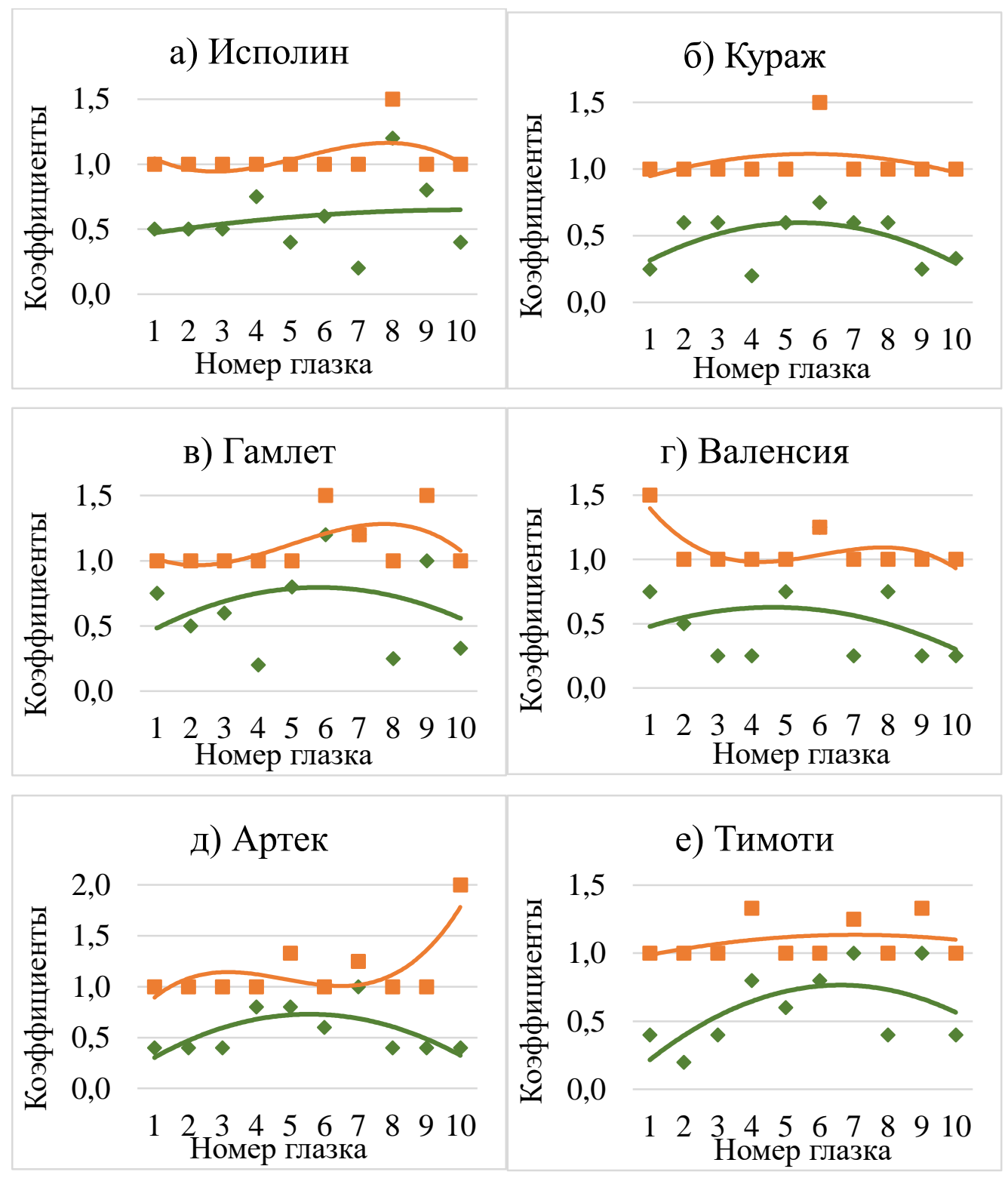

Рис. 2. Коэффициенты эмбрионального плодоношения (К1) и плодоносности (К2) — гибридных форм винограда 
Плодоводство и виноградарство Юга России № 68(2), 2021 г.

Bыводы. Основываясь на результатах изучения эмбрионального плодоношения и плодоносности винограда в умеренно-континентальных условиях центральной зоны виноградарства Краснодарского края, была установлена закономерность неодинаковой закладки и дифференциации эмбриональных соцветий у разных гибридов столового винограда Исполин, Кураж, Гамлет, Валенсия, Артек, Тимоти, а также дифференцированные показатели коэффициентов плодоношения и плодоносности по длине побегов у изучаемых гибридов в условиях высокотемпературного стресса. Наиболее высокие показатели плодоношения и плодоносности в условиях повышенного температурного режима были у гибридов винограда Исполин, Гамлет, Тимоти и Артек.

\section{Литература}

1. Fox R. Ezriehungssysteme: Klimawandel und Minimalschnitt - past das zusammen? // Dt. Weinmag. 2009. № 20. P.27-30.

2. Keller M. The Science of Grapevines: Anatomy and Physiology. - Academic Press, 2015. $508 \mathrm{p}$.

3. Frioni, T., Pirez, F.J., Garavani, A., Poni, S., Gatti, M. Effects of calibrated delayed winter pruning on Vitis vinifera L. 'Pinot Noir' grapevines in relation to different training systems // Acta Horticulturae. 2020. 1276. P. 65-71.

4. Яцушко К.А. Кравченко Р.В. Влияние регуляторов роста на эмбриональную плодоносность темно-ягодного технического сорта винограда Каберне-Совиньон в условиях Анапо-Таманской зоны // Сборник статей по материалам X Всероссийской конференции молодых ученых, посвященной 120-летию И.С. Косенко, Краснодар, 26-30 ноября 2016 г. Краснодар: КубГАУ, 2017. С. 741-742.

5. Дикань А.П. Плодоносность почек винограда как результат прохождения ими первого критического периода. // Виноградарство и виноделие. 2015. № 45. С. 32-35.

6. Дикань А.П. Взаимосвязь между массой зимующих глазков и плодоносностью центральных почек у сортов винограда Аркадия и Сира. // Магарач. Виноградарство и виноделие. 2017. № 4. С. 26-28.

7. Павлюченко Н.Г. Зимина Н.И. Потенциальная плодоносность сортов винограда при размножении в культуре in vitro // Магарач. Виноградарство и Виноделие. 2018. № 3 (105). C. 30-32

8. Martínez-Moreno A., Sanz F., Yeves A., Gil-Muñoz R., Martínez V., Intrigliolo D.S., Buesa I. Forcing bud growth by double-pruning as a technique to improve grape composition of Vitis vinifera L. cv. Tempranillo in a semi-arid Mediterranean climate // Scientia Horticulturae, 2019. Vol. 256. 108614.

9. Ganter B. Kleinterrassen wie bewirtschaften? // Bad.Winzer. - 2009. - N 3. P. 33-35 
10. Pandeliev S., Angelov L. Study on the Yield and Quakity of the Grape Cv. Tempranillo Depending on loading with Winter buds // Bulg.J.agr.Sc. 2005. Vol.11, N 3. P.289-301.

11. Milien M., Renault-Splimont A, Cookson S.J. Visualization of the 3D structure of the graft union of grapevine using X-ray tomography // Scientia Horticulturae. 2012. Vol. 144. P. 130-140.

12. Матузок Н.В. Трошин Л.П. Оптимизация технологии возделывания винограда на основе использования метода прогнозирования урожайности [Электронный ресурс] // Политематический сетевой электронный научный журнал Кубанского государственного аграрного университета. 2015. № 105. C. 1000-1034. URL: (дата обращения: 23.01.2019)

13. Буйвал Р.А. Тихомирова Н.А. Сравнительный анализ потенциальной плодоносности сортов винограда в хозяйствах южного берега Крыма // Русский виноград. 2017. № 5. С. 166-174.

14. Егоров Е.А., Серпуховитина К.А., Петров В.С. Состояние и перспективы научного обеспечения устойчивого развития виноградарства // Виноделие и виноградарство. 2008. № 3. С. 6-8.

15. Макарова Г.А. Плодоносность побегов винограда в условиях умеренно засушливой и колонной степи алтайского приобья // Достижения науки и техники АПК. 2008. № 7. С. 26-28

16. Кузьмина Т.И. Матузок Н.В. Особенности формирования эмбриональной и фактической плодоносности сортов винограда различного происхождения // Научное обеспечение агропромышленного комплекса: сборник трудов VI Всероссийская научно-практическая конференция молодых ученых, Краснодар, 26-28 ноября 2012 г. Краснодар, 2012. С. 151-153.

17. Spring J.-L., Ferretti M. Influence du rendement sur la qualite des raisins et des vins de Carminoir cultive au Tessin // Rev.suisse Vitic.Arboric.Hortic. 2007. Vol. 39, № 6. P.361-364. - Bibliogr.: p.363.

18. Vingione M., Meglioraldi S. La carica di gemme ottimale per Ancellota e Lambruschi // inform.agr. 2007. N 3. P.69-73

19. Li-Mallet A., Rabot A., Geny-Denis L. Factors Controlling Inflorescence Primordia Formation of Grapevine: What Role in Latent Bud Fruitfulness? // A Review. Canadian Journal of Botany. 2015. 94 (3). P. 147-163

20. Ollig W. Tafeltrauben - eine neue Obstart // Obstbau. 2003. Jg.28, N 8. S. 410-414.

21. Каширина Д.А. Оценка потенциальной плодоносности клонов европейских сортов винограда в условиях западного предгорно-приморского района Крыма. // Известия сельскохозяйственной науки Тавриды. 2015. № 4 (167). С.43-47.

22. Влияние способов содержания почвы на эмбриональную плодоносность почек и фитосанитарное состояние винограда / В.С. Петров [и др.] // Виноделие и виноградарство. 2005. № 3. С. 42.

23. Никольский М.А. Использование метода микрофокусной рентгенографии при оценке эмбриональной плодоносности глазков винограда. // Успехи современного естествознания. 2017. № 5. С. 56-60.

24. Цику Д.М., Гусев С.Э., Петров В.С. Отклик эмбриональной плодоносности столовых сортов винограда на стрессовые условия среды обитания в Волгоградской области // Научные труды СКФНЦСВВ. Т. 23. Краснодар: СКФНЦСВВ, 2019. C. 141-144.

25. Цику Д.М., Гусев С.Э., Петров В.С. Отзыв современных столовых сортов винограда на острозасушливые условия юга России и их влияние на эмбриональную плодоносность // Виноделие и виноградарство. 2019. № 2. С. 4-7. 
26. Петров В.С., Алейникова Г.Ю., Марморштейн А.А. Агроэкологическое зонирование территории для оптимизации размещения сортов, устойчивого виноградарства и качественного виноделия: монография. Краснодар: ФГБНУ СКФНЦСВВ, 2020. 138 с.

27. Агрометеорологические бюллетени по территории Краснодарского края / Краснодар: Краснодарский краевой центр по гидрометеорологии и мониторингу окружающей среды, 2020.

\section{References}

1. Fox R. Ezriehungssysteme: Klimawandel und Minimalschnitt - past das zusammen? // Dt. Weinmag. 2009. № 20. P.27-30.

2. Keller M. The Science of Grapevines: Anatomy and Physiology. - Academic Press, 2015. 508 p.

3. Frioni, T., Pirez, F.J., Garavani, A., Poni, S., Gatti, M. Effects of calibrated delayed winter pruning on Vitis vinifera L. 'Pinot Noir' grape-vines in relation to different training systems // Acta Horticulturae. 2020. 1276. P. 65-71.

4. Yacushko K.A. Kravchenko R.V. Vliyanie regulyatorov rosta na embrional'nuyu plodonosnost' temno-yagodnogo tekhnicheskogo sorta vinograda kaberne-sovin'on v usloviyah Anapo-Tamanskoj zony // Sbornik statej po materialam X Vserossijskoj konferencii molodyh uchenyh, posvyashchennoj 120-letiyu I.S. Kosenko, Krasnodar, 26-30 noyabrya 2016 g. Krasnodar: KubGAU, 2017. S. 741-742.

5. Dikan' A.P. Plodonosnost' pochek vinograda kak rezul'tat prohozhdeniya imi pervogo kriticheskogo perioda. // Vinogradarstvo i vinodelie. 2015. № 45. S. 32-35.

6. Dikan' A.P. Vzaimosvyaz' mezhdu massoj zimuyushchih glazkov i plodonosnost'yu central'nyh pochek u sortov vinograda Arkadiya i Sira. // Magarach. Vinogradarstvo i vinodelie. 2017. № 4. S. 26-28.

7. Pavlyuchenko N.G. Zimina N.I. Potencial'naya plodonosnost' sortov vinograda pri razmnozhenii v kul'ture in vitro // Magarach. Vinogradarstvo i Vinodelie. 2018. № 3 (105). S. 30-32

8. Martínez-Moreno A., Sanz F., Yeves A., Gil-Muñoz R., Martínez V., Intrigliolo D.S., Buesa I. Forcing bud growth by double-pruning as a technique to improve grape composition of Vitis vinifera L. cv. Tempranillo in a semi-arid Mediterranean climate // Scientia Horticulturae, 2019. Vol. 256. 108614. P. 33-35

9. Ganter B. Kleinterrassen wie bewirtschaften? // Bad.Winzer. - 2009. - N 3. -

10. Pandeliev S., Angelov L. Study on the Yield and Quakity of the Grape Cv. Tempranillo Depending on loading with Winter buds // Bulg.J.agr.Sc. 2005. Vol.11, N 3. P. 289-301.

11. Milien M., Renault-Splimont A, Cookson S.J. Visualization of the 3D structure of the graft union of grapevine using X-ray tomography // Scientia Horticulturae. 2012. Vol. 144. P. 130-140.

12. Matuzok N.V. Troshin L.P. Optimizaciya tekhnologii vozde-lyvaniya vinograda na osnove ispol'zovaniya metoda prognozirovaniya urozhajnosti [Elektronnyj resurs] // Politematicheskij setevoj elektronnyj nauchnyj zhurnal Kubanskogo gosudarstvennogo agrarnogo universiteta. 2015. № 105. S. 1000-1034. URL: (data obrashcheniya: 23.01.2019)

13. Bujval R.A. Tihomirova N.A. Sravnitel'nyj analiz potencial'noj plodonosnosti sortov vinograda v hozyajstvah yuzhnogo berega Kryma // Russkij vinograd. 2017. № 5. S. 166-174. 
14. Egorov E.A., Serpuhovitina K.A., Petrov V.S. Sostoyanie i perspektivy nauchnogo obespecheniya ustojchivogo razvitiya vinogradarstva // Vinodelie i vinogradarstvo. 2008. № 3. S. 6-8.

15. Makarova G.A. Plodonosnost' pobegov vinograda $\mathrm{v}$ usloviyah umerenno zasushlivoj i kolonnoj stepi altajskogo priob'ya // Dostizheniya nauki i tekhniki APK. 2008. № 7. S. 26-28

16. Kuz'mina T.I. Matuzok N.V. Osobennosti formirovaniya embrional'noj i fakticheskoj plodonosnosti sortov vinograda razlichnogo proiskhozhdeniya // Nauchnoe obespechenie agropromyshlennogo kompleksa: sbornik trudov VI Vserossijskaya nauchno-prakticheskaya konferenciya molodyh uchenyh, Krasnodar, 26-28 noyabrya 2012 g. Krasnodar, 2012. S. 151-153.

17. Spring J.-L., Ferretti M. Influence du rendement sur la qualite des raisins et des vins de Carminoir cultive au Tessin // Rev.suisse Vitic. Arboric. Hortic. 2007. Vol. 39, № 6. P.361-364. - Bibliogr.: p.363.

18. Vingione M., Meglioraldi S. La carica di gemme ottimale per Ancellota e Lambruschi // inform.agr. 2007. N 3. P.69-73

19. Li-Mallet A., Rabot A., Geny-Denis L. Factors Controlling Inflorescence Primordia Formation of Grapevine: What Role in Latent Bud Fruitfulness? // A Review. Canadian Journal of Botany. 2015. 94 (3). P. 147-163

20. Ollig W. Tafeltrauben - eine neue Obstart // Obstbau. 2003. Jg.28, N 8. S. 410-414.

21. Kashirina D.A. Ocenka potencial'noj plodonosnosti klonov evropejskih sortov vinograda $\mathrm{v}$ usloviyah zapadnogo predgorno-primorskogo rajona Kryma. // Izvestiya sel'skohozyajstvennoj nauki Tavridy. 2015. № 4 (167). S.43-47.

22. Vliyanie sposobov soderzhaniya pochvy na embrional'nuyu plodonosnost' pochek i fitosanitarnoe sostoyanie vinograda / V.S. Petrov [i dr.] // Vinodelie i vinogradarstvo. 2005. № 3. S. 42.

23. Nikol'skij M.A. Ispol'zovanie metoda mikrofokusnoj rentgenografii pri ocenke embrional'noj plodonosnosti glazkov vinograda. // Uspekhi sovremennogo estestvoznaniya. 2017. № 5. S. 56-60.

24. Ciku D.M., Gusev S.E., Petrov V.S. Otklik embrional'noj plodonosnosti stolovyh sortov vinograda na stressovye usloviya sredy obitaniya v Volgogradskoj oblasti // Nauchnye trudy SKFNCSVV. T. 23. Krasnodar: SKFNCSVV, 2019. S. 141-144.

25. Ciku D.M., Gusev S.E., Petrov V.S. Otzyv sovremennyh stolovyh sortov vinograda na ostrozasushlivye usloviya yuga Rossii i ih vliyanie na embrional'nuyu plodonosnost' // Vinodelie i vinogradarstvo. 2019. № 2. S. 4-7.

26. Petrov V.S., Alejnikova G.Yu., Marmorshtejn A.A. Agroekologicheskoe zonirovanie territorii dlya optimizacii razmeshcheniya sortov, ustojchivogo vinogradarstva i kachestvennogo vinodeliya: monografiya. Krasnodar: FGBNU SKFNCSVV, 2020. 138 s.

27. Agrometeorologicheskie byulleteni po territorii Krasnodarskogo kraya / Krasnodar: Krasnodarskij kraevoj centr po gidrometeorologii i monitoringu okruzhayushchej sredy, 2020. 